\title{
Serological and Molecular-Based Diagnosis of Toxoplasma gondii in Galliformes by using ToxPK1 gene
}

\author{
Farman Ullah Khan ${ }^{1}$, Nageen Hussain ${ }^{2}$ \\ ${ }^{1}$ M.S Microbiology and Molecular Genetics, University of the Punjab, Pakistan \\ ${ }^{2}$ Assistant Professor, Microbiology and Molecular Genetics, University of the Punjab, Pakistan
}

\begin{tabular}{l} 
Article Info \\
\hline Article history: \\
Received:11 September 2020 \\
Revised: 02 November2020 \\
Accepted:03 November 2020 \\
\hline Keywords: \\
Zoonosis, \\
Toxoplasmagondii, \\
Galliformes, \\
Prevalence, \\
ToxPK1 gene \\
Paper Type : \\
Research Article \\
\hline Corresponding Author: \\
Farman Ullah Khan \\
Email: \\
microbiologist88@gmail.com
\end{tabular}

\section{Article Info}

Article history:

\section{0}

\begin{abstract}
Purpose: The zoonosis caused by Toxoplasmagondii is known to be the third worldwide parasitic infectious disease. The living life, including human, chickens, cows and goats are at high risk because of its bulky circulation in the universe. The study was conducted to diagnoseT. gondii in Galliformes. The main objective of this study was to compare VetLine Toxoplasma with ToxPK1 gene as a marker for the detection of T. gondii. Study Design: An Experimental study.

Subjects and Methods: The study subjects involved were 35 broilers in which $80 \%$ were females and $20 \%$ were males.

Results: It was displayed that the female broilers have a little high rate of prevalence (29.63\%) as compared to male broilers (25\%).

Conclusion: It was concluded that VetLine Toxoplasma in which protein $A / G$ fixes to all IgGs subclasses from various mammalian species and the use of ToxPKI gene as a molecular marker for the detection of $T$. gondiiwere $100 \%$ matched. To eradicate and control this neglected zoonosis, there is an urgency need for risk factors control mechanisms; secondly specific, rapid and inexpensive diagnostic and treatment approaches.
\end{abstract}

\section{Introduction}

Toxoplasma gondii is one of the most prominent protozoan parasite causing a serious and neglected zoonotic infection which is known as toxoplasmosis. It has a global distribution of zoonosis. The parasite resides inside the cell, and it is obligate in nature. Warm blooded animals, mostly birds, human, domestic and wildlife are at higher risk (Al-nasrawi, 2014). The birds are the major reservoirs of the parasite which are often hunted by felids. Moreover, the birds can be the prospective host of this coccidian by their lengthy flying habit, feeding on the ground, etc. (Godoi,2010). The parasite is very prevalent among the human population. Based on the geographical area its frequency usually differs and nearly every third person is having toxoplasmosis in Iran ( Hamzavi et al., 2007). Numerous species of animals, including sheep, goats and cow's milk might be a source of toxoplasmosis transmission among the human population (Powell et al., 2001).

Chicken (Gallus domesticus) is regarded as one of the most significant in the epidemiology of $T$. gondii diseases as they are an effective cat infection source. They excrete oocysts resistant to any type of harsh environmental conditions. After eating contaminated chicken meat, people can get sick ( Dubey, 2010). It is considered to be the third most 
prevalent food-borne parasitic disease which needs hospitalization (Vaillant et al., 2005). Through molecular, serological and histological approaches, toxoplasmosis can be easily diagnosed. Blood, milk, extracts of infected tissue or liquid drained from muscles, thoracic cavity of aborted fetuses are suitable samples for the diagnosis of toxoplasmosis. Sabinfeldman dye test, modified agglutination, indirect fluorescence antibody assay, direct agglutination test, latex agglutination, enzyme linked immunosorbent assay and immunosorbent agglutination assay are some of the diagnostic techniques used for the detection of humoral antibodies.

For the treatment of toxoplasmosis mainly two widely drugs are used which include, sulphadiazine and pyrimethamine having the ability to stop the vigorous duplication of the parasite, but not completely destroy the parasite. Apart from these, atovaquone, spiramycin and clindamycine have been reported to treat severe cases of toxoplasmosis ( Castro, 2019; Fricker-Hidalgo et al., 2009). The disease in healthy persons is almost symptomless, but it can lead to serious issues or even death in immunosuppressed persons if not handled wisely. Thus, medical emergency therapy is necessary and the development of effective vaccine is the need of time to prevent toxoplasmosis. Moreover, moral cleanliness measures should be maintained to prevent the disease.

The main objective of this study was to compare VetLine Toxoplasma with ToxPK1 gene as a marker for the detection of $T$. gondii.

\section{Methodology and Procedures}

\section{Blood Sample collection}

A total of 35 blood specimens were collected from various poultry slaughter house with closed system and are from different farms of district Lahore, Punjab-Pakistan.

\section{Collection of serum from blood}

Serum was isolated from blood by centrifuging at $2000 \mathrm{rpm}$ for 15-20 minutes. It was then shifted to the eppendorf tubes, labeled and stored at $-20{ }^{\circ} \mathrm{C}$ which was further used frsergica screening.

\section{Extraction and detection of DNA}

Deoxyribonucleic acid (DNA) was extracted and detected in all the blood samples as per standard protocol ( Sambrook \& Fritsch, 1989).

\section{Molecular screening}

ToxPK1 gene amplification was performed by using conventional PCR. With the help of Primer3 (v.0.4.0) software, primer's (F: 5'CAGATTCATCGAATCCGAGC3'\&R: 5'AGAGAATCTCGCAGATGACG3') were designed. Following standard protocol a $50 \mu 1$ reaction was accomplished (Thermo Scientific), started with initial denaturation temperature on $95{ }^{\circ} \mathrm{C}$ for 5 minutes, the second denaturation on $95{ }^{\circ} \mathrm{C}$ for 1 minute, annealing temperature was $57{ }^{\circ} \mathrm{C}$ for 30 seconds and the extension temperature was $72{ }^{\circ} \mathrm{C}$ for 45 seconds. The 
temperature after extension was $72{ }^{\circ} \mathrm{C}$ for 5 minutes. A total of 30 cycles repeats were kept of the amplified product. Via electrophoresis, on $1.2 \%$ agarose gel, the amplified DNA fragments with 392 base pairs were tested and visualized under UV light illuminator.

\section{Results and Discussion}

The study was conducted to diagnose toxoplasmosis in Galliformes by using serological and molecular techniques. Based on specific features for instance, physical appearance of broilers, gender distribution was made like larger combs and wattles of male poultry birds, body, legs and foot sizes, etc. A total of 35 study subjects were involved in which $27(80 \%)$ were females and $8(20 \%)$ were males. The results were analyzed statistically by applying the "Fisher Exact Test". Statistics showed that the female's broilers have a slightly high prevalence rate $(29.63 \%)$ in comparison to male's broilers $(25 \%)$. However the $\mathrm{P}$ value was $>0.9999$, showed that the data is non-significant as $P$-value was $>0.05$. The sensitivity, specificity, positive and negative predictive values of $\operatorname{IgG}$ antibody for the clinical diagnosis of toxoplasmosis were calculated with the help of online diagnostic statistic test (https://www.medcalc.org/calc/diagnostic_test.php) (Table 3.2). From this, it was concluded that there is no significant prevalence difference of toxoplasmosis among female and male Broilers.

Table 3.3: Positive, negative predictive value and sensitivity, specificity of $\operatorname{IgG}$ antibody for the clinical diagnosis of toxoplasmosis

\begin{tabular}{ccccc}
\hline Antibody & $\begin{array}{c}\text { PPV } \\
(\%)\end{array}$ & $\begin{array}{c}\text { NPV } \\
(\%)\end{array}$ & $\begin{array}{c}\text { Sensitivity } \\
(\%: 95 \% \text { CI })\end{array}$ & $\begin{array}{c}\text { Specificity } \\
(\%: 95 \text { CI })\end{array}$ \\
IgG & 100 & 100 & $100(69.15-100)$ & $100(86.28-100)$ \\
\hline Source: Authors & & & &
\end{tabular}

\section{Molecular Screening}

All the samples were subject to molecular based diagnosis targeting ToxPK1 gene of T. gondii. The purpose was to confirm the sensitivity and specificity of serological based diagnosis (ELISA). The primer-F (5'CAGATTCATCGAATCCGAGC3' and primer-R (5'AGAGAATCTCGCAGATGACG3' of ToxPK1 gene were designed by using primer 3 (v.0.4.0) software. The primers and position of the primers (F \& R) on exon 8 of $T$. gondii PK1 gene were confirmed by using NCBI Primer Blast. Gradient PCR was performed for the optimization of ToxPK1 gene. The best bands were observed at $57{ }^{\circ} \mathrm{C}$ annealing temperature along with the standard ladder. The results under molecular screening were the same as on ELISA $(100 \%)$. This means that VetLine Toxoplasma is very much sensitive and specific test for the diagnosis of toxoplasmosis as the benefit of these ELISA kits is the use of Protein A / $\mathrm{G}$, which binds all IgG subclasses from various mammalian species, including all IgGs that bind Protein A and Protein G. Moreover, as compared to ELISA, conventional PCR is more expensive, time consuming, so there is a need to investigate and discover new diagnostic techniques which are easily available, cheap, and fast having a high standard of sensitivity and specificity for the diagnosis of toxoplasmosis. 


\section{Discussion}

Toxoplasma gondii is found intracellularly zoonotic infectious agent globally, leading to several unknown consequences in different hosts including nearly all mammals and birds ( Dubey \& Beattie, 1989). It has the capability to poison all nucleated cells, and it is one of the well-known neglected eukaryotic infectious agent. It is very important both in medicine and veterinary terms ( Liu et al., 2012). Toxoplasma gondii is related to huge global financial losses (Khan et al., 2017). Globally for toxoplasmosis infection, the birds are considered to be the main middle hosts. The infections are transmitted to birds like chickens, crow etc. as the soil based birds feeding on soil contaminated with the parasite oocysts. Cats are mainly wellknown for recurrence of $T$. gondii infection. Earlier studies reported that, the pathogen causes significant deaths in different species of wild bird's world-wide (Murao et al., 2008; Wu et al., 2011).

In birds, poultry also serve as middle hosts of this neglected pathogen and easily victimized world-wide and even causing human population complications (Devada et al., 1998). In Europe, studies indicate that the main source of human toxoplasmosis is raw meat. In another study, it was reported that raw or undercooked intake of poultry add to the large proportion of infection in human population (Cook et al., 2000; Kapperud et al., 1996). Local products like consumption of goat milk, cured, dried or smoked meat, raw oysters and clams or mussels are considered to be the potential risk factors for toxoplasmosis (Jones et al., 2009). It is understood that chicken are greatly proven to toxoplasmosis, nevertheless, this parasitic exposure to poultry was decreased by intensive husbandry and viable $T$. gondii could not be identified in an extensive study of chicken breast samples from retail meat stores in the United States. ELISA reported just a few positive results (1.3\%) from a population of more than 2000 chickens (Dubey et al., 2005). The threat of human ailments with poultry meat can proliferate with increased demands for organic meat. From backyard chicken, viable T. gondii have been often isolated (Dubey, 2010). Moreover, expanding the market share by eating raw items like, chicken burgers and sausages increases the risk of toxoplasmosis in human population. This parasite appears to have chosen locations in the chickens. A variety of viable tissue cysts seems to be found in different parts of the body. A recent review showed that, in relation to positive $T$. gondii infection, the brain, heart and muscle have been scored comparatively high (Opsteegh et al., 2016).

In this study, the overall seroprevalence of the disease was $28.57 \%$ (CI 95\% $=14.64$ to $46-30 \%$ ). This figure is quite higher than the study conducted in other cities of Pakistan like Mardan, Khyber Pakhtunkhwa in which out of 536 sera samples, 101(18.85\%) were found seropositive for T. gondii ( Mahmood et al., 2014). Similarly, (12.5\%) seroprevalence was reported from USA (Dubey et al., 2008), which is quite lower than this figure. Unlike this study, another study reported from Punjab-Pakistan that there is no anti-toxoplasma antibody in poultry (Zaki, 1995). On the other hand, from Indonesia, Poland and Vietnam, the seroprevalence was $24.4 \%, 30 \%, 24.2 \%$ respectively which has quite similar figures with respect to this study. Similarly, from Taiwan, a seroprevalence study on wild birds was conducted using MAT, in which the overall seroprevalence was $23.35 \%$ (CI 95\% $=19.17 \%$ $27.53 \%$ ), which is in close similarity with the present study. In short, the variations in the

Copyright (C) 2020, Journal of Scientific Research in Medical and Biological Sciences (JSRMBS), Under 
prevalence rate may be due to the geographical differences of the population, the socioeconomic status of the environment, traditions and customs and their lifestyle. It was reported that domestic chicken are identified as a good indicator of contamination in the environment by T.gondii oocysts because of their habit on ground. Another study on the seroprevalence was conducted in free range and caged chickens by using Indirect hemagglutination antibody testin which the prevalence was $20.70 \%$ and $5.90 \%$ respectively ( Mahmood et al., 2014).

Another study was conducted on the seroprevalence of $T$. gondiiin Taiwan, where overall seroprevalence was $23.35 \%$ (CI 95\% $=19.17 \%-27.53 \%$ ). In the group of "birds of prey" overall seroprevalence was $(25.73 \%)$, birds living in fresh water, marine and terrestrial system have $(34.29 \%)$ seroprevalence, while in "ground feeding-birds" the seroprevalence was reported at (18.12\%) respectively(Chen et al., 2015). In this study, the overall seroprevalence of the disease was recorded at $28.57 \%$. From this, it is concluded that there is no significant prevalence difference of toxoplasmosis among female and male broilers. In contrast, seroprevalence study from Mardan, KPK Pakistan, reported high anti-toxoplasma antibodies among female's broilers $(22.20 \%)$ as compared to male's $(17.80 \%)$ in which the P value $<0.05$ was considered as statistically significant ( Mahmood et al., 2014). A study from University Al-Qadissiya Iraq reported that using B1 gene for detection of T. gondii as target by using real-time PCR in human and chicken is a quick and sensitive molecular technique (Al-nasrawi et al., 2014), while from literature review, there is no study reported in which ToxPK1 gene was used as a marker for the detection of this protozoan parasite in poultry using conventional PCR. Hence, using conventional PCR by targeting ToxPK1 gene as a $T$. gondii indicator in poultry was reported for the first time in Pakistan.

\section{Conclusion and Suggestion}

In this study, the overall seroprevalence of the disease was recorded at $28.57 \%$. From this, it is concluded that there is no significant prevalence difference of toxoplasmosis among female and male broilers. This study helps us to recognize the risk factors responsible for this zoonotic problem. It needs additional analysis among poultry population as it enters into the food chain and how it affects the human population at the end. Also, there is a need for specific, rapid and inexpensive diagnostic and treatment methods which may play an important role in controlling this neglected zoonotic problem in both poultry and human population.

\section{Conflict of Interest}

The authors of the article declare no conflict of interest.

\section{Funding:}

The authors received no funding for conducting this study. 


\section{References}

Al-nasrawi, H. A. H., Naser, H. H., \& Kleaf, S. F. (2014). Molecular detection of Toxoplasma gondii in human and chicken by real-time PCR technique. Int J Ad Res, 2, 1023-1027.

Castro, P. D. J., \& Dubey, J. P. (2019). Toxoplasma gondii-the facts. Companion Animal, 24(6), 300-305.

Chen, J. C., Tsai, Y. J., \& Wu, Y. L. (2015). Seroprevalence of Toxoplasma gondii antibodies in wild birds in Taiwan. Research in Veterinary Science, 102, 184-188.

Cook, A. J. C., Holliman, R., Gilbert, R. E., Buffolano, W., Zufferey, J., Petersen, E., ... \& Dunn, D. T. (2000). Sources of toxoplasma infection in pregnant women: European multicentre case-control studyCommentary: Congenital toxoplasmosis-further thought for food. Bmj, 321(7254), 142-147.

Devada, K., Anandan, R., \& Dubey, J. P. (1998). Serologic prevalence of Toxoplasma gondii in chickens in Madras, India. The Journal of parasitology, 84(3), 621-622.

Dubey, J. P., \& Beattie, C. P. (1988). Toxoplasmosis of animals and man. CRC Press, Inc..

Dubey, J. P., Hill, D. E., Jones, J. L., Hightower, A. W., Kirkland, E., Roberts, J. M., ... \& Sreekumar, C. (2005). Prevalence of viable Toxoplasma gondii in beef, chicken, and pork from retail meat stores in the United States: risk assessment to consumers. Journal of Parasitology, 91(5), 1082-1093.

Dubey, J. P., Huong, L. T. T., Lawson, B. L., Subekti, D. T., Tassi, P., Cabaj, W., ... \& Su, C. (2008). Seroprevalence and isolation of Toxoplasma gondii from free-range chickens in Ghana, Indonesia, Italy, Poland, and Vietnam. Journal of Parasitology, 94(1), 6871.

Dubey, J. P. (2010). Toxoplasma gondii infections in chickens (Gallus domesticus): prevalence, clinical disease, diagnosis and public health significance. Zoonoses and Public Health, 57(1), 60-73.

Fricker-Hidalgo, H., Bulabois, C. E., Brenier-Pinchart, M. P., Hamidfar, R., Garban, F., Brion, J. P., ... \& Pelloux, H. (2009). Diagnosis of toxoplasmosis after allogeneic stem cell transplantation: results of DNA detection and serological techniques. Clinical Infectious Diseases, 48(2), e9-e15

Godoi, F. S. L. D., Nishi, S. M., Pena, H. F. D. J., \& Gennari, S. M. (2010). Toxoplasma gondii: diagnosis of experimental and natural infection in pigeons (Columba livia) by serological, biological and molecular techniques. Revista Brasileira de Parasitologia Veterinária, 19(4), 237-243.

Hamzavi, Y., Mostafaie, A., \& Nomanpour, B. (2007). Serological prevalence of toxoplasmosis in meat producing animals. Iranian Journal of Parasitology, 7-11.

Jones, J. L., Dargelas, V., Roberts, J., Press, C., Remington, J. S., \& Montoya, J. G. (2009). Risk factors for Toxoplasma gondii infection in the United States. Clinical Infectious Diseases, 49(6), 878-884.

Kapperud, G., Jenum, P. A., Stray-Pedersen, B., Melby, K. K., Eskild, A., \& Eng, J. (1996). Risk factors for Toxoplasma gondii infection in pregnancy: results of a prospective case-control study in Norway. American journal of epidemiology, 144(4), 405-412. 
Kelly, L. M., \& Alworth, L. C. (2013). Techniques for collecting blood from the domestic chicken. Lab Animal, 42(10), 359-361.

Khan, M. U., Rashid, I., Akbar, H., Islam, S., Riaz, F., Nabi, H., ... \& Singla, L. D. (2017). Seroprevalence of Toxoplasma gondii in South Asian countries. Rev. Sci. Tech, 36, 981-996.

Liu, Q., Singla, L. D., \& Zhou, H. (2012). Vaccines against Toxoplasma gondii: status, challenges and future directions. Human vaccines \& immunotherapeutics, 8(9), 13051308.

Mahmood, Z. U., Zahid, M., Sthanadar, A. A., Shah, M., \& Hussain, A. (2014). Seroprevalence of Toxoplasma gondii infection in Gallus domesticus of district Mardan, Khyber Pakhtunkhwa, Pakistan. Pakistan Journal of Zoology, 46(6).

Murao, T., Omata, Y., Kano, R., Murata, S., Okada, T., Konnai, S., ... \& Onuma, M. (2008). Serological survey of Toxoplasma gondii in wild waterfowl in Chukotka, Kamchatka, Russia and Hokkaido, Japan. Journal of Parasitology, 94(4), 830-833.

Opsteegh, M., Maas, M., Schares, G., \& van der Giessen, J. (2016). Relationship between seroprevalence in the main livestock species and presence of Toxoplasma gondii in meat (GP/EFSA/BIOHAZ/2013/01) An extensive literature review. Final report. EFSA Supporting Publications, 13(2), 996E.

Powell, C. C., Brewer, M., \& Lappin, M. R. (2001). Detection of Toxoplasma gondii in the milk of experimentally infected lactating cats. Veterinary parasitology, 102(1-2), 2933.

Sambrook, J., \& Fritsch, E. F.; Maniatis, T.(1989) Molecular cloning: a laboratory manual 2nd edition. New York. USA: Cold Spring Harbor Laboratory,

Vaillant, V., Valk, H. D., Baron, E., Ancelle, T., Colin, P., Delmas, M. C., ... \& Jougla, E. (2005). Foodborne infections in France. Foodbourne Pathogens \& Disease, 2(3), 221232.

Wu, S. M., Huang, S. Y., Fu, B. Q., Liu, G. Y., Chen, J. X., Chen, M. X., ... \& Ye, D. H. (2011). Seroprevalence of Toxoplasma gondii infection in pet dogs in Lanzhou, Northwest China. Parasites \& Vectors, 4(1), 64.

Zaki, M. (1995). Seroprevalence of Toxoplasma gondii in domestic animals in Pakistan. Journal of Pakistan Medical Association, 45(1). 